\title{
Expression Pattern of Several Flowering-related Genes during Flower Bud Formation in Rhododendron × pulchrum 'Oomurasaki'
}

\author{
Kyeong-Seong Cheon ${ }^{1 * *}$, Akira Nakatsuka ${ }^{2}$, Keisuke Tasaki ${ }^{1 * * *}$ and Nobuo Kobayashi ${ }^{2 *}$ \\ ${ }^{1}$ Center for Integrated Research in Science, Shimane University, Matsue 690-8504, Japan \\ ${ }^{2}$ Faculty of Life and Environmental Science, Shimane University, Matsue 690-8504, Japan
}

To investigate the relationship between the development of floral buds and the expression pattern of floweringrelated genes, observation of floral organ development and expression analysis of $R p F T, R p S O C 1, R p L F Y, R p T F L 1$, $R p C E N$, and $R p A P 3$ were carried out from July to August 2011 of the evergreen azalea 'Oomurasaki'. After floral meristem development, floral organs, such as sepals, petals, stamens, and carpels, were observed subsequently on the floral meristems. The expression level of RpTFL1 gradually decreased with floral meristem development; however, the expression level of $R p F T$ and $R p L F Y$ increased continuously until carpel development and that of $R p A P 3$ began to increase with stamen development. RpSOC1 and RpCEN showed an irregular expression pattern during floral bud development. These results suggest that the period of floral organ development can be determined by the expression pattern of $R p T F L 1, R p F T, R p L F Y$, and $R p A P 3$ in evergreen azalea 'Oomurasaki'.

Key Words: evergreen azalea, expression analysis, floral developmental stage, flowering genes.

\section{Introduction}

Flowering is an important event in the plant life cycle. In the flowering process, floral bud formation is promoted by environmental and genetic factors, which suggests that differentiation of floral buds is triggered environmentally and genetically in many plant species. Thus, studies of floral bud formation must consider not only environmental factors, but also genetic factors to better understand the process of floral bud formation (Ausín et al., 2005).

Recent genetic investigations with the model plant Arabidopsis thaliana have led to the discovery of numerous genes that control flowering (Araki, 2001; Shannon and Meeks-Wagner, 1991; Weigel and Meyerowitz, 1994). Genetic analysis of flowering time mutants has identified four major pathways controlling the timing of floral bud formation: photoperiod (day length), vernalization (temperature), gibberellins (GAs),

Received; November 30, 2012. Accepted; May 31, 2013.

This study was supported by Grants-in-Aid for Scientific Research (KAKENHI nos. 22580032 and 23241076) from the Japan Society for the Promotion of Science (JSPS).

* Corresponding author (E-mail: nkobayashi@life.shimane-u.ac.jp).

** Present address: Floriculture Division, National Institute of Horticultural and Herbal Science, Suwon 441-440, Korea.

*** Present address: Research Faculty of Agriculture, Hokkaido University, Sapporo 060-8589, Japan. and autonomous factors. An intricate interplay of the above pathways promotes floral transition via the transcriptional regulatory activity of several floral pathway integrators, including FLOWERING LOCUS T (FT), SUPPRESSOR OF OVEREXPRESSION OF CONSTANS 1 (SOCl), and LEAFY (LFY). FT proteinproduct flowering signals triggered by the photoperiod and produced in the vascular tissue of leaves are transported to the shoot apical meristem (SAM; Corbesier et al., 2007). FT protein interacts with a transcription factor, FLOWERING LOCUS D, which is expressed only in the SAM, to activate transcription of the floral meristem identity gene APETALA1 (APl). In contrast to FT, FLOWERING LOCUS C, and SHORT VEGETATIVE PHASE, which are controlled by temperature, impair responses to the $F T$ and $S O C 1$ signals by directly repressing expression (Amasino, 2010; Lee et al., 2007; Searle et al., 2006). SOC1 is also activated by $F T$, which is an age-dependent and GAinduced mechanism (Lee and Lee, 2010). When SOC1 is induced at the SAM, SOCl directly activates $L F Y$. Subsequently, specification of the floral meristem occurs in conjunction with floral meristem identity genes such as $L F Y$ and $A P 1$. These genes play a key role in the initiation of both the floral meristem and floral organs (Weigel and Meyerowitz, 1994; Weigel et al., 1992). During floral meristem formation, TERMINAL FLOWER 1 (TFL1) prevents the expression of $L F Y$ and $A P 1$ 
(Shannon and Meeks-Wagner, 1991), and both genes activate transcription factors as floral organ identity genes, termed $\mathrm{ABC}$ model genes (Huala and Sussex, 1992; Weigel and Meyerowitz, 1994). According to the ABC model, class A genes control the formation of sepals, class $\mathrm{A}$ and $\mathrm{B}$ genes together regulate petal formation, class $\mathrm{B}$ and $\mathrm{C}$ genes control stamen formation, and class $\mathrm{C}$ genes function alone to regulate formation of the carpel. AP1 and APETALA2 are class A genes, APETALA3 (AP3) and PISTILLATA are B-function genes, which interact as a heterodimer (Yang et al., 2003), and AGAMOUS is a C-function gene. Several flowering-related genes have been expressed in herbal and woody plants; however, expression analysis of the genetic factors that control floral bud formation in evergreen azaleas has not been undertaken previously.

Rhododendron comprises approximately 1000 species and is the largest genus within the Ericaceae. Since the Edo era (1603-1867) in Japan, many horticultural cultivars have been bred from wild Rhododendron species and are cultivated in gardens and pots (Kobayashi et al., 1995, 2000). Studies on the effect of environmental conditions, day length, and temperature on flowering of azaleas have led to different conclusions. The reason might be that different cultivars respond diversely. Molecular-level studies are needed to establish the period of floral bud formation during a single flowering season in azaleas. Among azaleas, $R$. × pulchrum 'Oomurasaki' is one of the most popular garden cultivars and is widely planted in Japan because of its vigorous growth and hardiness. With regard to flowering of 'Oomurasaki', the change from vegetative to reproductive growth occurs during summer and floral buds form at approximately $25^{\circ} \mathrm{C}$ under natural conditions. The floral meristem develops in late July in Japan, and the morphological changes that occur in the shoot apex under natural conditions have been studied previously (Kosugi and Kondo, 1955).

In previous studies, we reported the isolation of putative flowering-related genes in 'Oomurasaki', such as FT, SOC1, LFY, TFL1, CENTRORADIALIS (CEN), which has been shown to act (like TFL1) by indirectly interacting with FLORICAULA in Antirrhinum (Coen et al., 1990), and $A P 3$ homologs. The expression pattern of these genes and shoot growth were used to determine the putative timing of the initiation of floral bud formation (Cheon et al., 2011, 2012); however, the expression pattern of these genes, in relation to morphological changes of the floral meristem in the shoot apex, remains unclear. In this study, the evergreen azalea 'Oomurasaki', which has a single flowering season, was used to examine microscopically the developmental stage of floral organs during floral bud formation, because 'Oomurasaki' has larger shoots and floral buds than other evergreen azaleas. In addition, expression analysis by reverse-transcription-quantitative PCR (RT-qPCR) was performed to understand better the expression pattern of RpFT, RpSOC1, RpLFY, RpTFL1, $R p C E N$, and RpAP3 during floral bud formation. Although the expression of $F T$ in leaves is essential for flowering in model plants, we analyzed the expression of these flowering-related genes in shoot tips, which comprised the shoot apical parts including the SAM and stem, because Kotoda et al. (2010) and Mimida et al. (2011) reported the importance of FT-like gene expression in apical buds of apple. A further objective was to determine the putative period of floral bud formation in $R$. × pulchrum 'Oomurasaki'.

\section{Materials and Methods}

\section{Plant material and sampling}

Plants of $R$. × pulchrum 'Oomurasaki' were grown on the Shimane University campus, Matsue, Japan. The average temperature in Matsue during the experimental period is shown in Figure 1. The plants were not pruned or subjected to any chemical treatment during the experimental period.

To investigate the expression of several floweringrelated genes at each stage of floral organ development, the stages of floral organ development were observed in fresh, intact shoots on 24 July and 7 August. Also, shoots $(n=3)$ were sampled at each developmental stage, i.e. no visible floral meristems, floral meristems, sepals, petals, stamens, carpels, and complete floral bud on shoot tips (2-mm-long segment including the stem) (see Fig. 2A). To investigate floral organ development, shoot tips $(n=10)$ were observed from July to August 2011. After removal of the bracts, the shoot apices were fixed in FAA ( $5 \%$ formaldehyde, $5 \%$ acetic acid, $45 \%$ ethanol, and $45 \%$ water) and stored at $4{ }^{\circ} \mathrm{C}$ until observation. The developmental stage of each organ was assessed following Kosugi and Kondo (1955). For investigation of the mRNA levels during floral bud formation, shoots $(n=10)$ that had sprouted and developed from branches in April 2011 were collected weekly as a mixed sample. Shoot tips, which consisted of 1-cm-long segments including the SAM and a portion of the stem but no

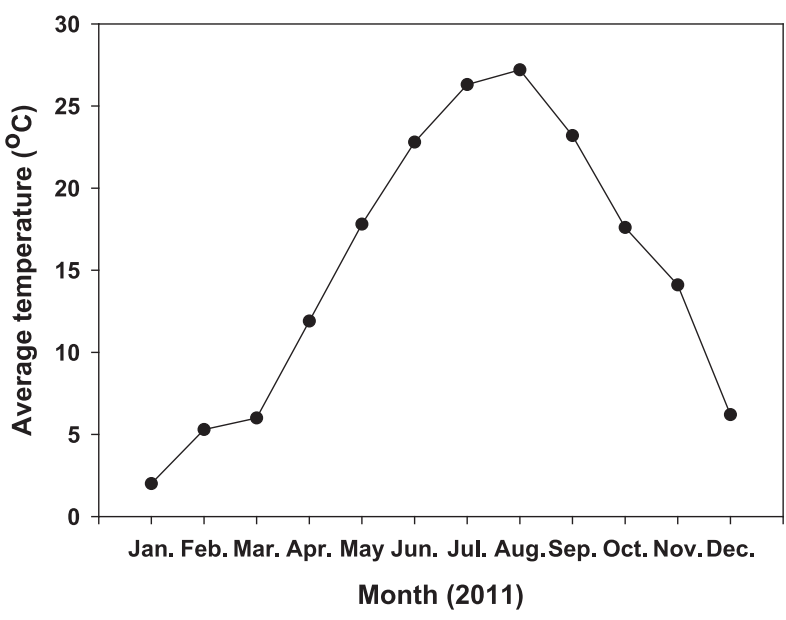

Fig. 1. Average monthly temperature in Matsue, Japan, in 2011. 
(A)
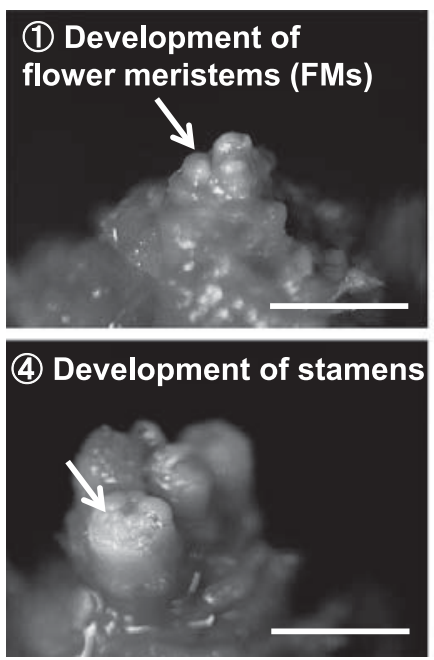
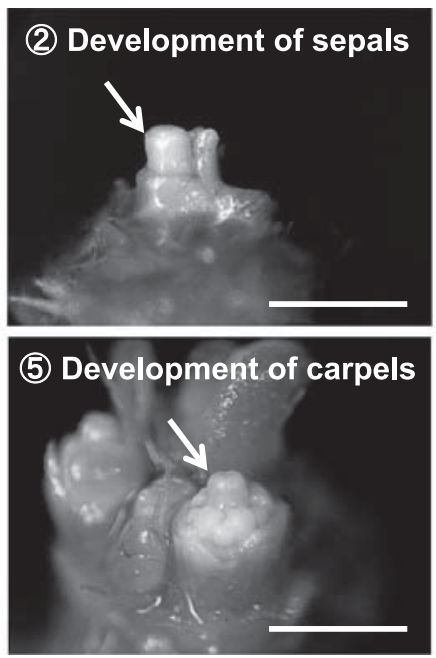
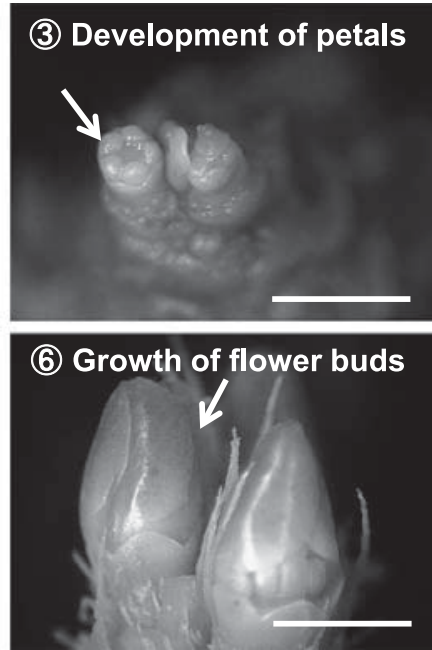

(B)

\begin{tabular}{|c|c|c|c|c|c|c|c|c|c|}
\hline Development & 3 July & 10 July & 17 July & 24 July & 31 July & 7 August & 14 August 2 & 1 August & 28 August \\
\hline No visible FMs & 10 & 10 & 6 & 1 & & & & & \\
\hline FMs & & & 3 & 4 & 3 & & & & \\
\hline Sepals & & & 1 & 4 & 4 & 1 & & & \\
\hline Petals & & & & 1 & 1 & 5 & & & \\
\hline Stamens & & & & & 2 & 3 & 7 & & \\
\hline Carpels & & & & & & 1 & 3 & 10 & 10 \\
\hline
\end{tabular}

Fig. 2. (A) Micrographs of the shoot apex of 'Oomurasaki' at different stages of floral organ development. Bars = $1 \mathrm{~mm}$. (B) Frequency of shoot apices $(n=10)$ at each developmental stage of floral bud formation from 3 July to 28 August 2011.

leaves, were sampled from 3 July to 7 August, and apical buds were collected from 14 to 28 August. The FT gene and its homologs respond to the circadian clock in woody plants (Hsu et al., 2006). Thus, to avoid day-specific differences in the mRNA expression of light-responsive genes and to facilitate comparison of gene expression in different samples during the flowering season, all of the samples were collected between 13:00 and 15:00. During sampling, the shoots were collected as a mixed sample, and the samples (only one biological replicate) were used for expression analysis. All of the samples for RNA extraction were immediately frozen in liquid nitrogen and stored at $-80^{\circ} \mathrm{C}$ until extraction.

\section{RNA extraction and $c D N A$ synthesis}

Total RNA was extracted from the samples using the RNeasy Plant Mini Kit (QIAGEN, Hilden, Germany). To avoid DNA contamination, $1 \mu \mathrm{g}$ total RNA from each sample underwent RNase-free DNaseI (TaKaRa Bio, Shiga, Japan). The non-RT samples underwent RT-qPCR to check for DNA contamination. In the RT-qPCR assay, $1 \mu \mathrm{l}$ of the non-RT samples was used as the template in a $20 \mu \mathrm{l}$ RT-qPCR assay mix containing $10 \mu \mathrm{l}$ SYBR Premix Ex Taq II (TaKaRa Bio) and $0.25 \mu \mathrm{M}$ of each primer. Each RT-qPCR assay was conducted using a Thermal Cycler Dice Real-Time System (TaKaRa) with initial denaturation of $30 \mathrm{~s}$ at $95^{\circ} \mathrm{C}$, followed by 40 cycles of $5 \mathrm{~s}$ at $95^{\circ} \mathrm{C}$ and $30 \mathrm{~s}$ at $60^{\circ} \mathrm{C}$. No amplification of the ACTIN and Histone H3 genes was observed, and thus DNA in the total RNA samples (non-RT samples) was completely digested by the treatment. The total RNA treated with DNase I was then reverse-transcribed by oligo (dT) and ReverTra Ace reverse transcriptase (Toyobo Co., Osaka, Japan) in accordance with the manufacturer's instructions. The synthesized first strand of cDNA was used for expression analyses.

Expression analysis by reverse-transcription quantitative PCR

Expression analysis of the RpFT, RpSOC1, RpLFY, $R p T F L 1, R p C E N$, and $R p A P 3$ genes was conducted with RT-qPCR. The primer pairs used for the RT-qPCR assay were reported previously (Cheon et al., 2011, 2012). In the RT-qPCR assay, $0.5 \mu \mathrm{l}$ of the cDNA samples was used as the template in a $20 \mu \mathrm{l}$ RT-qPCR assay mix containing $10 \mu \mathrm{l}$ SYBR Premix Ex Taq II (TaKaRa Bio) and $0.25 \mu \mathrm{M}$ of each primer. Each RT-qPCR assay was conducted using a Thermal Cycler Dice Real-Time System (TaKaRa) with initial denaturation of $30 \mathrm{~s}$ at $95^{\circ} \mathrm{C}$, followed by 40 cycles of $5 \mathrm{~s}$ at $95^{\circ} \mathrm{C}$ and $30 \mathrm{~s}$ at $60^{\circ} \mathrm{C}$. Each cDNA sample was analyzed in three technical replicates. The data for each PCR reaction were 
calculated using the difference in the threshold cycle values $(\Delta \mathrm{Ct})$ between the samples (target genes and reference genes) to calculate the relative amounts of the template present. Because normalization against three or more validated reference genes was considered the most appropriate and universally applicable method (Derveaux et al., 2010), two reference genes (ACTIN and Histone H3) were used for normalization of cDNA in this study. The relative expression value was calculated as the standard [1] using the minimum value for each gene, and the mean and standard error (SE) were calculated from the relative expression between the reference genes.
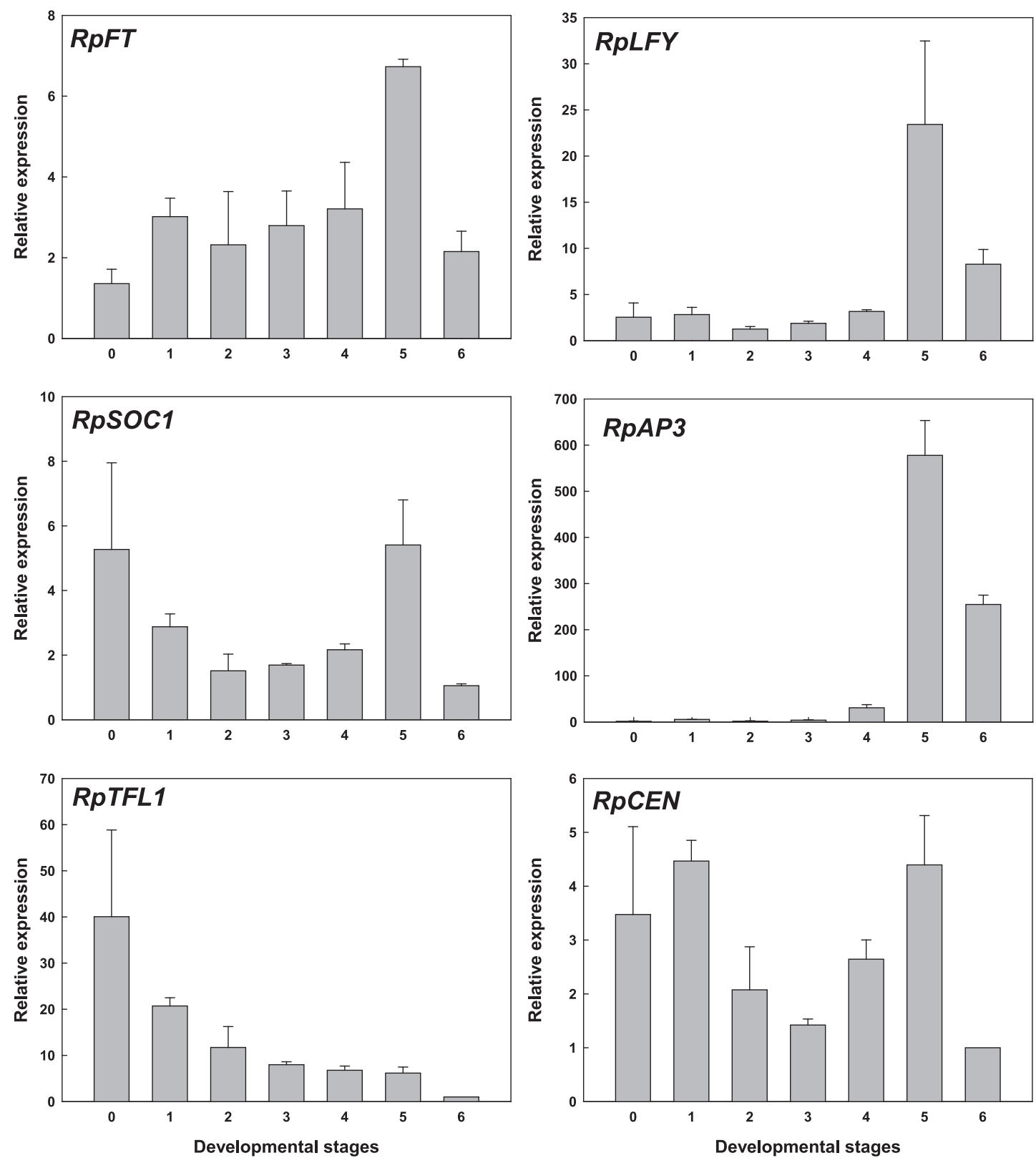

Fig. 3. Expression pattern of RpFT, RpSOC1, RpLFY, RpTFL1, RpCEN, and RpAP3 at each stage of floral organ development in 'Oomurasaki'. Each stage of floral organ formation was collected on 24 July and 7 August. RT-qPCR was performed with gene-specific primers (Cheon et al., 2011, 2012). Data are the mean $\pm \mathrm{SE}(\mathrm{n}=3$; normalized against both Histone H3 and ACTIN). Development of the apex from the vegetative to the inflorescence stage: stage 0 , vegetative meristem; stage 1, floral meristem development; stage 2, sepal development; stage 3 , petal development; stage 4, stamen development; stage 5, carpel development; stage 6, growth of floral bud. 
Expression analysis of flowering-related genes in both random samples and developmental-stage samples

To investigate the expression pattern of floweringrelated genes in relation to the floral organ developmental stage, each stage was sampled after microscopic observation of apical buds on 24 June and 7 August (Fig. 2A). The results of the expression analysis are shown in Figure 3. RpTFL1 expression decreased continuously from before visible development of the floral meristem to carpel development. RpSOC1 expression decreased from before floral meristem development until sepal and petal development, but then
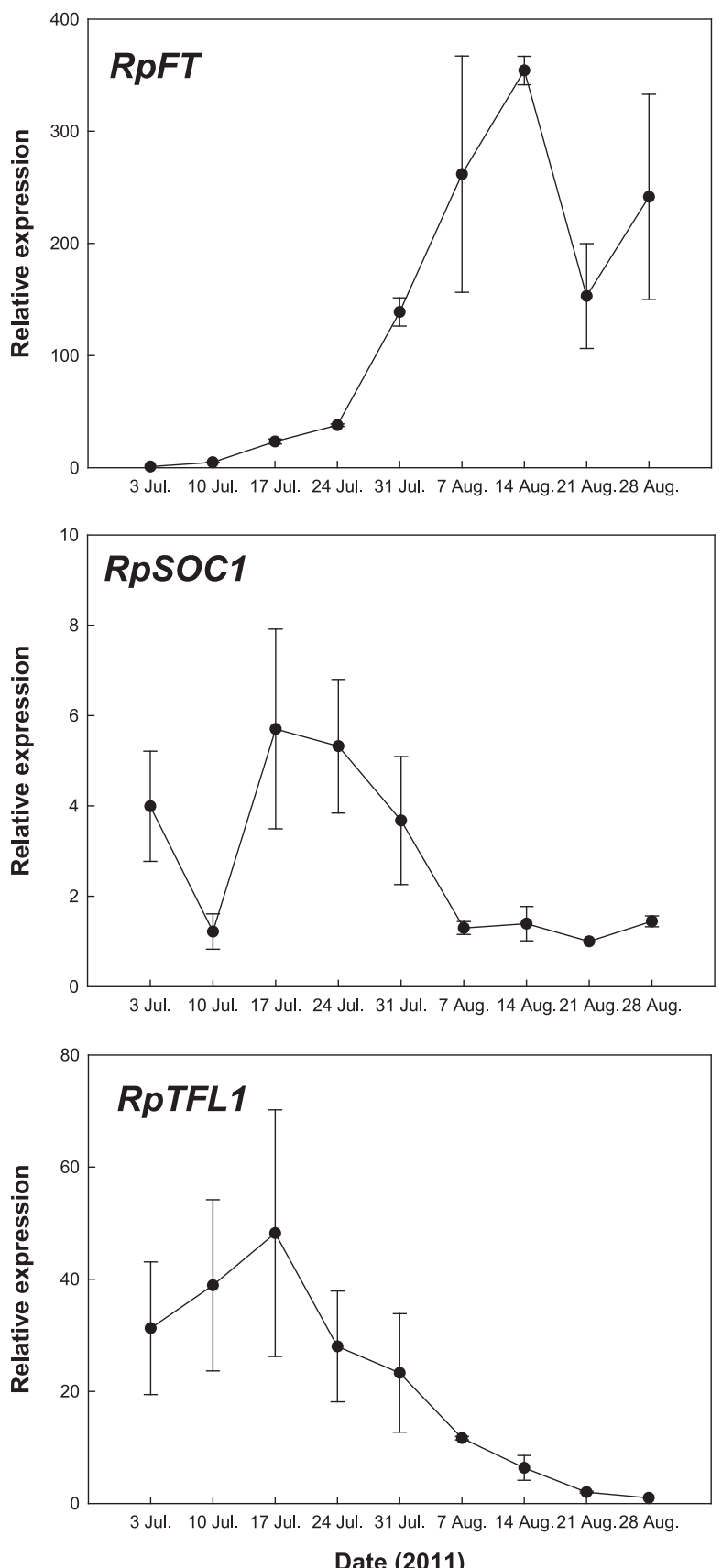

increased at the stamen and carpel development stages. Expression of RpFT and RpLFY increased coincident with carpel development but was otherwise relatively constant during floral meristem development. RpAP3 expression increased during stamen and carpel development. RpCEN expression showed an irregular pattern at each stage of floral organ development.

The expression pattern of RpFT, RpSOCl, RpLFY, $R p T F L 1, R p C E N$, and RpAP3 was analyzed in random samples of the shoot apex and apical bud, which were collected weekly from 3 July to 28 August (Fig. 4), and the results were compared with the microscopic
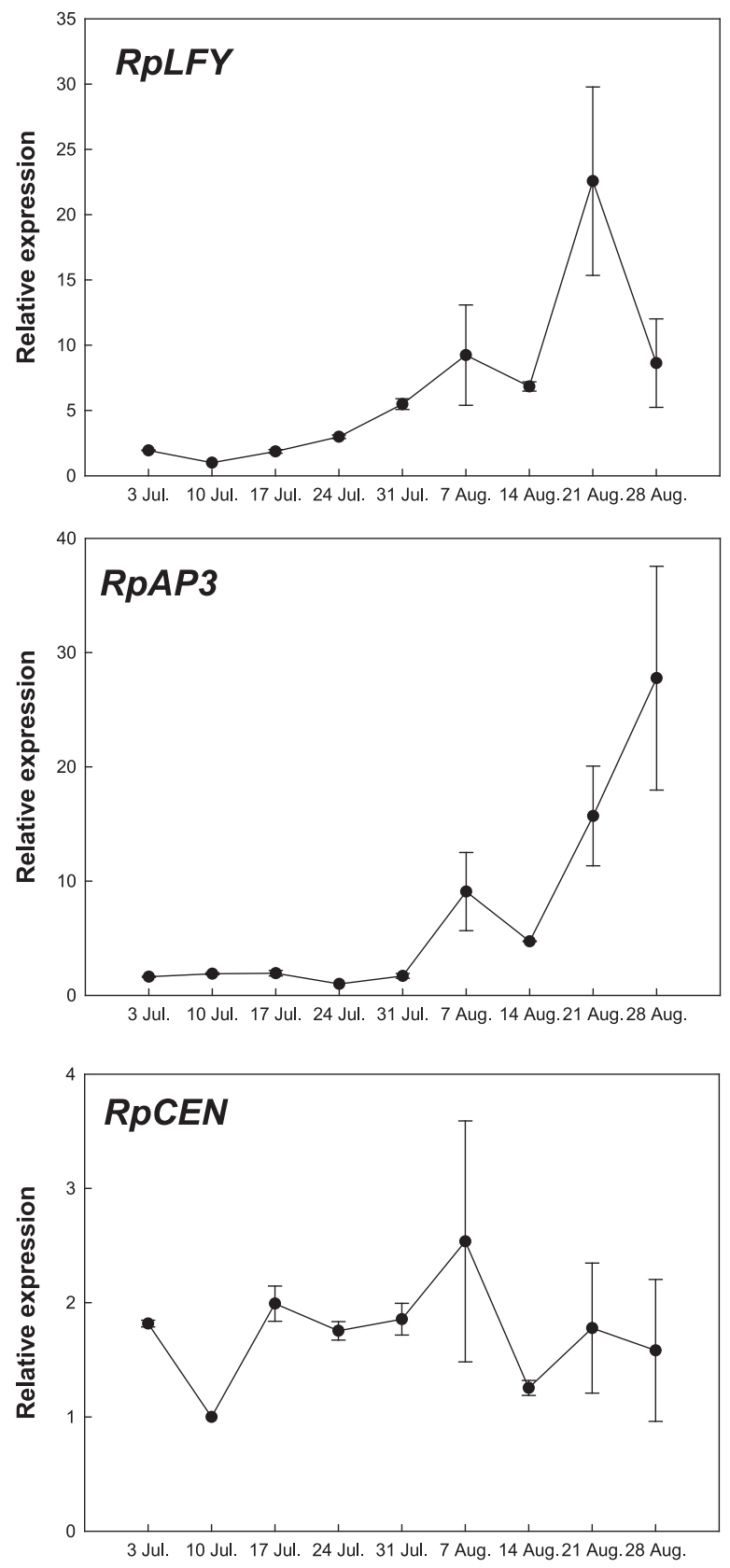

Date (2011)

Fig. 4. Expression pattern of RpFT, RpSOC1, RpLFY, RpTFL1, RpCEN, and RpAP3 in the random samples of 'Oomurasaki' shoot tips and apical buds. The samples were collected weekly from 3 July to 28 August. RT-qPCR was performed with gene-specific primers (Cheon et al., 2011, 2012). Data are the mean $\pm \mathrm{SE}(\mathrm{n}=3$; normalized against both Histone H3 and ACTIN). 
observations of floral bud development (Fig. 2B). RpTFL1 and RpSOC1 expression simultaneously decreased after expression peaked on 17 July, which corresponded with the appearance of floral meristems. $R p F T$ was expressed continually from 10 July to 14 August, which corresponded with the development of stamens and carpels, and $R p L F Y$ was expressed continually from 17 July to 21 August, corresponding to the development of carpels. The expression of RpAP3 increased on 7 August (Fig. 4), which corresponded with the development of stamens and carpels (Fig. 2B), and continued to increase until completion of floral bud formation. RpCEN expression showed an irregular pattern during the experimental period.

\section{Discussion}

Generally, floral bud formation in evergreen azaleas is initiated during summer in Japan, and the floral buds develop after the initiation of flowering (Kosugi and Kondo, 1955). Bodson (1983) reported that initiation of scales and initiation of the floral meristem in azaleas represent distinct stages of flower initiation, and that subsequent stages involved the development of the most advanced floral meristems into a complete flower. As reported by Kosugi and Kondo (1955), floral meristems were first observed in late July at approximately $25^{\circ} \mathrm{C}$ under natural conditions in Japan, and stamen and carpel development was observed in all samples in late August. In the present study (Fig. 2), the results of microscopic observation of the shoot apex are in agreement with the findings of Kosugi and Kondo (1955) and Bodson (1983). In the observation period, peak expression of RpTFL1 coincided with floral meristem development, and subsequently the expression level decreased during floral bud development. Coincident with decreased RpTFLl expression, the RpFT and RpLFY expression levels started to increase with floral meristem development and increased more substantially with carpel development. While $R p F T$ and $R p L F Y$ expression levels increased strongly, the RpAP3 expression level also began to increase with stamen development (Figs. 3 and 4).

The expression pattern of FT, SOC1, LFY, TFL1, and $A P 3$ during floral bud formation has been studied in Arabidopsis (Huala et al., 1992; Liu et al., 2009; Shannon and Meeks-Wagner, 1991; Wagner, 2009), and the expression pattern of homologs of these Arabidopsis genes has been investigated in other plant species. In apple (Malus domestica), Mimida et al. (2011) examined the expression pattern of flowering-related genes during the transition from the vegetative to reproductive phases in apical buds using in situ hybridization. When the committed vegetative meristem is converted into the early inflorescence meristem, a marked decrease in MdTFL1 expression is observed in the rib meristem zone. Subsequently, the expression levels of MdFT and AFL2, which is a $L F Y$ homolog in apple, are upregulated in the leaf primordia and the early inflorescence meristem. In the next stage, AFL2 is highly expressed in the floral meristems and continues to be expressed at high levels in the developing floral organs in the following stage. Esumi et al. (2007) reported that the amount of TFL1 homolog expression in Japanese pear decreased considerably before floral differentiation began with the formation of the apical meristem dome, whereas the expression level of the $L F Y$ homolog increased at the floral meristem formation stage and remained at a relatively high level in the floral meristem after the floral differentiation stage. Hu et al. (2012) showed that, after floral meristem formation in Sinofranchetia chinensis, expression of SIchAP3-2 was detected in the carpels during advanced developmental stages. Although RpAP3 expression in this study was in agreement with the report of $\mathrm{Hu}$ et al. (2012), more experiments, such as in situ hybridization, are needed for confirmation of the spatial expression of the $A P 3$ homolog because $A P 3$ and its homolog are expressed in the petals and stamens in Arabidopsis and other plants. Unlike the expression patterns of RpFT, RpLFY, RpTFL1, and RpAP3, the expression pattern of $R p S O C l$ did not correspond with the developmental stage of floral organs (Fig. 3) and random floral buds (Fig. 4). Although SOCl expression in the apical meristem is essential for the phase transition (Searle et al., 2006), the expression level of SOC1 in the shoot tip seems to be unstable because the shoot tip includes young leaves and the stem. Thus, the present results indicate that the expression patterns of $R p F T$, $R p L F Y, R p T F L 1$, and RpAP3 correspond with morphological changes during floral development of 'Oomurasaki'.

Interestingly, with regard to the relationship between floral development and the expression pattern of flowering-related genes, Hättasch et al. (2008) reported that if the expression pattern of $F T, A F L$, and TFL1 homologs in apple shoots was investigated by quantitative transcription analysis, the timing of floral bud formation could be identified. In evergreen azalea 'Oomurasaki', the expression pattern of RpFT, RpLFY, $R p T F L 1$, and $R p A P 3$ was used to determine the period of floral bud formation. However, the expression pattern of RpSOC1 and RpCEN was unsuitable to determine the floral bud formation period, because expression of these genes was irregular in both random and developmentalstage samples (Figs. 3 and 4) and increased mainly in the period of floral bud dormancy during seasonal flowering (Cheon et al., 2012). Thus, on the basis of the present results, with weekly sampling of shoot tips and apical buds of 'Oomurasaki' after flower abscission, we propose that the period of floral organ development can be determined from the expression pattern of RpTFL1, $R p F T, R p L F Y$, and RpAP3 (Fig. 5).

The differences in the expression pattern of $R p F T$, $R p L F Y, R p T F L 1$, and RpAP3 and changes in the developmental stage of the shoot apex suggested that the expression pattern of these genes can be used to 


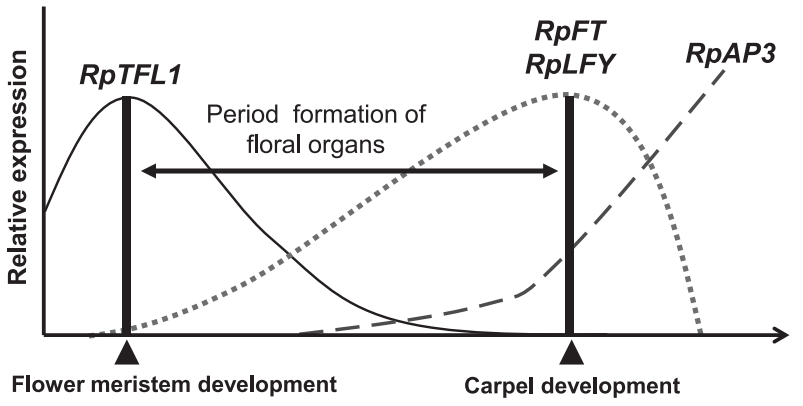

Fig. 5. Putative model of floral bud formation on the basis of the expression pattern of RpTFL1, RpFT, RpLFY, and RpAP3 in random samples of 'Oomurasaki' shoot apices.

determine the period of floral development in $R . \times$ pulchrum 'Oomurasaki'. The knowledge gained from this study on the evergreen azalea $R . \times$ pulchrum 'Oomurasaki' may be applicable to other evergreen azaleas and helpful to analyze factors that regulate flowering and floral bud formation.

\section{Literature Cited}

Amasino, R. 2010. Seasonal and developmental timing of flowering. Plant J. 61: 1001-1013.

Araki, T. 2001. Transition from vegetative to reproductive phase. Curr. Opin. Plant Biol. 4: 63-68.

Ausín, I., C. Alonso-Blanco and J. M. Martínez-Zapater. 2005. Environmental regulation of flowering. Int. J. Dev. Biol. 49: 689-705.

Bodson, M. 1983. Effect of photoperiod and irradiance on floral development of young plants of a semi-early and a late cultivar of azalea. J. Amer. Soc. Hort. Sci. 108: 382-386.

Cheon, K. S., A. Nakatsuka and N. Kobayashi. 2011. Isolation and expression pattern of genes related to flower initiation in the evergreen azalea Rhododendron $\times$ pulchrum 'Oomurasaki'. Sci. Hortic. 130: 906-912.

Cheon, K. S., A. Nakatsuka, K. Tasaki and N. Kobayashi. 2012. Seasonal changes in the expression pattern of floweringrelated genes in evergreen azalea 'Oomurasaki' (Rhododendron $\times$ pulchrum). Sci. Hortic. 134: 176-184.

Coen, E. S., J. M. Romero, S. Doyle, R. Elliott, G. Murphy and R. Carpenter. 1990. floricaula: a homeotic gene required for flower development in Antirrhinum majus. Cell 63: 13111322.

Corbesier, L., C. Vincent, S. H. Jang, F. Fornara, Q. Fan, I. Searle, A. Giakountis, S. Farrona, L. Gissot, C. Turnbull and G. Coupland. 2007. FT protein movement contributes to longdistance signaling in floral induction of Arabidopsis. Science 316: 1030-1033.

Derveaux, S., J. Vandesompele and J. Hellemans. 2010. How to do successful gene expression analysis using real-time PCR. Methods 50: 227-230.

Esumi, T., R. Tao and K. Yonemori. 2007. Relationship between floral development and transcription levels of $L E A F Y$ and TERMINAL FLOWER 1 homologs in Japanese pear (Pyrus pyrifolia Nakai) and Quince (Cydonia oblonga Mill.). J. Japan. Soc. Hort. Sci. 76: 294-304.

Hättasch, C., H. Flachowsky, D. Kapturska and M.-V. Hanke. 2008. Isolation of flowering genes and seasonal changes in their transcript levels related to flower induction and initiation in apple (Malus domestica). Tree Physiol. 28: 1459-1466.
Hsu, C.-Y., Y. Liu, D. S. Luthe and C. Yuceer. 2006. Poplar FT2 shortens the juvenile phase and promotes seasonal flowering. Plant Cell 18: 1846-1861.

Hu, J., J. Zhang, H. Shan and Z. Chen. 2012. Expression of floral MADS-box genes in Sinofranchetia chinensis (Lardizabalaceae): implications for the nature of the nectar leaves. Ann. Bot. 110: 57-69.

Huala, E. and M. Sussex. 1992. LEAFY interacts with floral homeotic genes to regulate Arabidopsis floral development. Plant Cell 4: 901-913.

Kobayashi, N., T. Handa, K. Yoshimura, Y. Tsumura, K. Arisumi and K. Takayanagi. 2000. Evidence for introgressive hybridization based on chloroplast DNA polymorphisms and morphological variation in wild evergreen azalea populations of the kirishima mountains, Japan. Edinb. J. Bot. 57: 209-219.

Kobayashi, N., R. Takeuchi, T. Handa and K. Takayanagi. 1995. Cultivar identification of evergreen azalea with RAPD Method. J. Japan. Soc. Hort. Sci. 64: 611-616.

Kosugi, K. and H. Kondo. 1955. Studies on the flower bud differentiation and development in some ornamental trees and shrubs. V. On the of flower bud differentiation and flower bud development in Chaenomeles extus-coccine CARR., Rhododendron obtusum PLANCH and R. Oomurasaki MAKINO. J. Japan. Soc. Hort. 23: 264-268 (in Japanese with English summary).

Kotoda, N., H. Hayashi, M. Suzuki, M. Igarashi, Y. Hatsuyama, S. Kidou, T. Igasaki, M. Nishiguchi, K. Yano, T. Shimizu, S. Takahashi, H. Iwanami, S. Moriya and K. Abe. 2010. Molecular characterization of Flowering Locus T-Like genes of apple (Malus domestica Borkh.). Plant Cell Physiol. 51: 561-575.

Lee, J. G. and I. H. Lee. 2010. Regulation and function of SOC1, a flowering pathway integrator. J. Exp. Bot. 61: 2247-2254.

Lee, J. H., S. J. Yoo, S. H. Park, I. D. Hwang, J. S. Lee and J. H. Ahn. 2007. Role of SVP in the control of flowering time by ambient temperature in Arabidopsis. Genes. Dev. 21: 397-402.

Liu, C., W. Xi, L. Shen, C. Tan and H. Yu. 2009. Regulation of floral patterning by flowering time genes. Dev. Cell 16: $711-$ 722.

Mimida, N., A. Ureshino, N. Tanaka, N. Shigeta, N. Sato, Y. Moriya-Tanaka, H. Iwanami, C. Honda, A. Suzuki, S. Komori and M. Wada. 2011. Expression patterns of several floral genes during flower initiation in the apical buds of apple (Malus $\times$ domestica Borkh.) revealed by in situ hybridization. Plant Cell Rep. 30: 1485-1492.

Searle, I., Y. He, F. Turck, C. Vincent, F. Fornara, S. Kröber, R. A. Amasino and G. Coupland. 2006. The transcription factor FLC confers a flowering response to vernalization by repressing meristem competence and systemic signaling in Arabidopsis. Genes Dev. 20: 898-912.

Shannon, S. and O. R. Meeks-Wagner. 1991. A mutation in the Arabidopsis TFL1 gene affects inflorescence meristem development. Plant Cell 3: 877-892.

Wagner, D. 2009. Flower morphogenesis: Timing is key. Dev. Cell 16: 621-622.

Weigel, D. and E. M. Meyerowitz. 1994. The ABCs of floral homeotic genes. Cell 78: 203-209.

Weigel, D., J. Alvarez, D. R. Smyth, M. F. Yanofsky and E. M. Meyerowitz. 1992. $L E A F Y$ controls floral meristem identity in Arabidopsis. Cell 69: 643-659.

Yang, Y., L. Fanning and T. Jack. 2003. The K domain mediates heterodimerization of the Arabidopsis floral organ identity proteins, APETALA3 and PISTILLATA. Plant J. 33: 47-59. 